\title{
Numerical study of macrosegregation in Aluminum alloys solidifying on uneven surfaces
}

\author{
Deep Samanta, Nicholas Zabaras * \\ Materials Process Design and Control Laboratory, Sibley School of Mechanical and Aerospace Engineering, \\ Cornell University, 188 Frank H.T. Rhodes Hall, Ithaca, NY 14853-3801, USA
}

Received 27 September 2004; received in revised form 15 March 2005

\section{Abstract}

Solidification of Aluminum alloys is modeled on uneven surfaces characterized by sinusoidal curves. Wavelengths and amplitudes of these surfaces are varied to study the effect of changing surface topography on fluid flow, macrosegregation and inverse segregation in the solidifying alloy. Solidification is initiated by convective heat removal from the uneven surfaces and simulations are carried out in both vertical and horizontal configurations. Stabilized finite element methods, recently used for modeling solidification in the presence of shrinkage and buoyancy driven flows, are used to discretize and solve the governing transport equations derived by volume averaging. The effect of varying amplitudes and wavelengths is observed in heat transfer, fluid-flow, macrosegregation and inverse segregation processes. In vertical solidification, inverse segregation, that usually occurs at the bottom of the cavities, is studied for different sinusoidal topographies quantified by a particular wavelength and amplitude. The fluid flow here is driven by a combination of shrinkage and thermosolutal buoyancy. Shrinkage driven flow arises due to different densities of solid and liquid phases. During horizontal solidification of an Aluminum alloy from uneven surfaces, thermosolutal buoyancy plays a dominant role in fluid flow and the effect of shrinkage is neglected by assuming the individual phase densities to be equal. Convection in this case is much stronger than that in the vertical case and large scale redistribution of the solute element occurs. To measure variation in macrosegregation with changing surface topography, global extent of segregation and difference between maximum and minimum solute concentrations are calculated for different amplitudes and wavelengths. In both the cases, the main aim is to quantify changes in macrosegregation due to changing surface topography accomplished by varying amplitudes or wavelengths or both.

(c) 2005 Published by Elsevier Ltd.

28 Keywords: Fluid flow; Surface topography; Sinusoid; Macrosegregation; Solidification of alloys; Volume-averaging; Inverse segregation

30

\section{Introduction}

Transport phenomenon during solidification of 32

${ }^{*}$ Corresponding author. Tel.: +1 607255 9104; fax: +1 607 2559401.

E-mail address: zabaras@cornell.edu (N. Zabaras).

URL: http://www.mae.cornell.edu/zabaras (N. Zabaras). alloys is a major cause of casting defects such as segregation, microvoids, hot tears, porosity, internal and surface cracks. Heat flow across metal and mold surfaces directly affects the phase change process and plays an 


\section{Nomenclature}

$A \quad$ amplitude of sinusoidal surface

$C_{0} \quad$ reference concentration

$c_{\mathrm{s}}, c_{1} \quad$ solid/liquid specific heats

$C$ solute concentration

$C_{\mathrm{e}} \quad$ eutectic concentration

$C_{\mathrm{l}_{0}} \quad$ initial concentration in the melt

d secondary dendrite arm spacing

$D_{1} \quad$ liquid solute diffusivity

$\boldsymbol{e}_{\mathrm{g}} \quad$ unity vector in direction of gravity

$f \quad$ liquid mass fraction

g gravity constant

GES global extent of segregation

$h \quad$ enthalpy

$h_{\text {conv }} \quad$ convection heat transfer coefficient

$h_{\mathrm{f}} \quad$ latent heat of fusion

$k_{1} \quad$ thermal conductivity of the melt

$k_{\mathrm{s}} \quad$ thermal conductivity of the solid

$K_{0} \quad$ permeability constant

$L_{\mathrm{s}} \quad$ projected length of sinusoidal surface

$m_{\text {liq }} \quad$ slope of the liquidus line

$m_{\text {sol }} \quad$ slope of the solidus line

$p \quad$ pressure

$T_{\mathrm{i}} \quad$ initial temperature of the melt

$T_{\mathrm{m}} \quad$ melting temperature

$T_{\mathrm{amb}} \quad$ ambient surrounding temperature
$T_{\mathrm{e}} \quad$ eutectic temperature

$T_{0} \quad$ reference temperature

$T$ temperature in the domain

$\boldsymbol{v} \quad$ averaged or superficial velocity

$|v|_{\max } \quad$ maximum velocity magnitude

Greek symbols

$\beta_{\mathrm{T}} \quad$ coefficient of thermal expansion

$\beta_{\mathrm{S}} \quad$ coefficient of solutal expansion

$\epsilon \quad$ volume fraction of liquid

$\Gamma \quad$ boundary of the physical domain

$\Gamma^{T} \quad$ part of the boundary subjected to Dirichlet conditions

$\Gamma^{q} \quad$ part of the boundary subjected to Neumann conditions

$\kappa \quad$ partition coefficient

$\mu \quad$ viscosity of the liquid

$\lambda$ wavelength of the sinusoidal surface

$\Omega \quad$ physical domain

$\rho_{10} \quad$ reference liquid density

$\rho_{1} \quad$ liquid density

$\rho_{\mathrm{s}} \quad$ solid density

$\rho$ density important role in determining freezing conditions within the metal. Solidification of alloys invariably leads to non-uniform distribution of solute known as macrosegregation, which refers to the large scale non-uniformity in the local average composition in a solidified casting or ingot. Convection significantly affects the final solute redistribution and macrosegregation in solidified castings. Different types of macrosegregation found in alloys are inverse segregation, banding segregation, centerline segregation, under-riser segregation, top-end segregation, ghost bands, freckles, channel segregation and Aor V-segregation. For an alloy solidifying upwards in a vertical cavity, the redistribution of solute is caused by the flow of solute rich liquid in the mushy zone due to solidification shrinkage. In this case, concentration of solute is higher near the bottom surface from where solidification initiates and this phenomenon is called inverse segregation. Inverse segregation is a leading cause of defects in castings solidified from below. In [1,2], Thevik and Mo modeled surface segregation in Aluminum alloys driven by exudation and solidification shrinkage. Air-gap formation in their model was expressed through a variable convective heat transfer coefficient at the boundary. Shrinkage driven flow was shown to play a significant role in inverse segregation observed near the end of the castings. In Refs. [3-6] too, shrinkage driven flow was shown to play an important role in inverse seg- 63 regation during vertical solidification of Aluminum- 64 Copper alloys. $\mathrm{Xu}$ and $\mathrm{Li}$ in $[7,8]$ modeled horizontal 65 solidification of an Aluminum-Copper alloy under the 66 influence of shrinkage and buoyancy driven convection. 67 They were the first to use a continuum model to incorpo- 68 rate density changes occurring during alloy solidification 69 and employed finite difference methods in all their 70 numerical examples. In Ref. [9], the authors studied 71 the combined effect of thermosolutal buoyancy and con- 72 traction driven flow on macrosegregation during the di- 73 rect chill casting of a round Al-Cu ingot. They also used 74 a microscopic grain growth model where solid back-dif- 75 fusion, solutal undercooling in the liquid and the effect 76 of different grain densities was incorporated. In [10,11], 77 modeling of directional solidification of binary and mul- 78 ti-component alloys is reported in a vertical cavity 79 including an investigation of the effect of gravity and 80 variable cavity width on macrosegregation. 81

Surface unevenness or imperfections play an impor- 82 tant role during early stages of solidification. They influ- 83 ence heat transfer rate and fluid flow in the melt, which 84 in turn affect solute redistribution, and morphology of 85 the evolving mushy and solid zones. Very often in the 86 casting industry, mold surfaces are given an artificial 87 topography to enhance heat transfer and wettability char- 88 
89 acteristics. In [12], experiments were reported involving 90 direct chill and continuous casting to study surface defects 91 in cast Aluminum alloys. Both smooth and sand blasted 92 molds were used to carry out casting experiments and 93 the effect of roughening the mold surface on the growth 94 front morphology was studied. Fig. 1 shows the impact 95 of both the molds on the front morphology and grain 96 structure in continuously cast ingots. The top left portion 97 shows a highly non-uniform shell thickness since the freez98 ing front morphology exhibits waviness or 'humps'. When 99 this ingot is inverted, the planar side of the ingot, which is 100 in contact with the mold, shows a columnar grain struc-

ture that is undesirable for subsequent metal processing operations. This ingot was cast with a smooth mold surface. The freezing front morphology becomes nearly parabolic as shown in the lower left when a sand blasted mold is used. Equiaxed grain structure forms on the planar side of the ingot as shown in the lower right half of Fig. 1. In the upper right portion of the same figure, non-uniformities are observed, which finally lead to the appearance of various defects on and just below the ingot surface. An engineered mold surface, used to control heat extraction in directional solidification, is shown in Fig. 2. The periodic groove topography allows multi-directional heat flow at the mold/shell interface. To obtain anticipated benefits the pitch or wavelength must be on the millimeter scale. Topographies generally range from unidirectional grooves to discrete recessions or cavities. Hector et al. in [13] derived analytical expressions correlating the effect of mold surface wavelength on contact pressure and gap nucleation at the mold-metal interface during solidification of pure Aluminum. The effect of uneven surface topography on solute redistribution and fluid flow during solidification of an alloy is an important theme that has not been previously investigated.
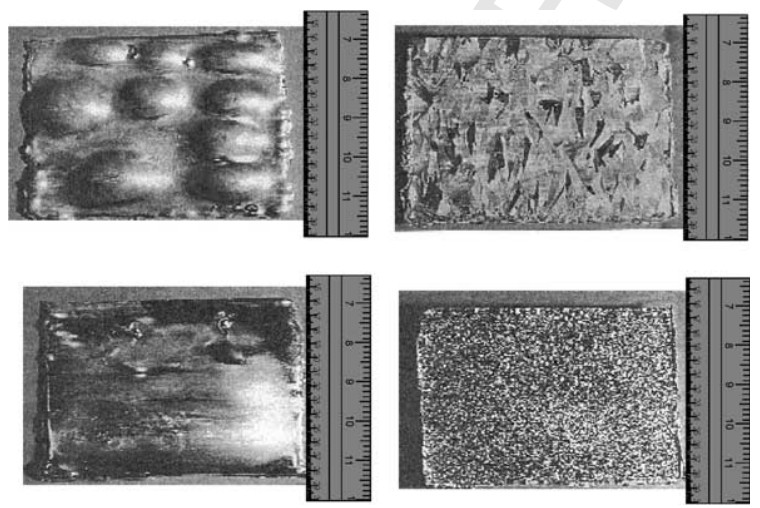

Fig. 1. Top shows non-uniform front and undesirable columnar grain structure on bottom side of ingot, respectively (smooth mold surface). Below shows parabolic front and desirable equiaxed grain structure on bottom side of ingot, respectively (sand blasted mold) (courtesy ALCOA Inc.).

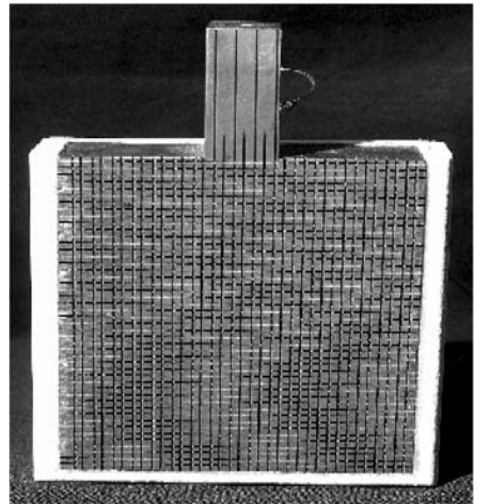

Fig. 2. A mold surface with periodic 'groove' topography to control heat extraction during directional solidification (courtesy ALCOA Inc.).

Box I. Governing transport equations for solidification of alloys

$$
\begin{aligned}
& \frac{\partial \rho(\boldsymbol{x}, t)}{\partial t}+\nabla \cdot(\rho(\boldsymbol{x}, t) \boldsymbol{v}(\boldsymbol{x}, t))=0, \quad \boldsymbol{x} \in \Omega \\
& \frac{\partial(\rho(\boldsymbol{x}, t) \boldsymbol{v}(\boldsymbol{x}, t))}{\partial t}+\nabla \cdot\left(\frac{\rho(\boldsymbol{x}, t) \boldsymbol{v}(\boldsymbol{x}, t) \boldsymbol{v}(\boldsymbol{x}, t)}{f(\boldsymbol{x}, t)}\right) \\
& =-\nabla p(\boldsymbol{x}, t)+\frac{p(\boldsymbol{x}, t)}{\epsilon(\boldsymbol{x}, t)} \nabla \epsilon(\boldsymbol{x}, t) \\
& +\nabla \cdot\left[\frac{\mu}{\rho_{1}}\left(\nabla(\rho(\boldsymbol{x}, t) \boldsymbol{v}(\boldsymbol{x}, t))+(\nabla(\rho(\boldsymbol{x}, t) \boldsymbol{v}(\boldsymbol{x}, t)))^{T}\right)\right] \\
& -\frac{\epsilon(\boldsymbol{x}, t) \mu}{K(\epsilon(\boldsymbol{x}, t))} \frac{\rho(\boldsymbol{x}, t)}{\rho_{1}} \boldsymbol{v}(\boldsymbol{x}, t)-\epsilon(\boldsymbol{x}, t) \rho_{\mathrm{l}_{0}} g\left[\beta_{\mathrm{T}}\left(T(\boldsymbol{x}, t)-T_{0}\right)\right. \\
& \left.+\beta_{\mathrm{S}}\left(C_{1}(\boldsymbol{x}, t)-C_{\mathrm{l}_{0}}\right)\right] \boldsymbol{e}_{\mathrm{g}}, \quad \boldsymbol{x} \in \Omega \\
& \frac{\partial(\rho(\boldsymbol{x}, t) h(\boldsymbol{x}, t))}{\partial t}+\nabla \cdot\left(\rho(\boldsymbol{x}, t) \boldsymbol{v}(\boldsymbol{x}, t) h_{1}(\boldsymbol{x}, t)\right) \\
& =\nabla \cdot\left[\left(\epsilon(\boldsymbol{x}, t) k_{1}+(1-\epsilon(\boldsymbol{x}, t)) k_{\mathrm{s}}\right) \nabla T(\boldsymbol{x}, t)\right], \quad \boldsymbol{x} \in \Omega \\
& \frac{\partial(\rho(\boldsymbol{x}, t) C(\boldsymbol{x}, t))}{\partial t}+\nabla \cdot\left(\rho(\boldsymbol{x}, t) \boldsymbol{v}(\boldsymbol{x}, t) C_{1}(\boldsymbol{x}, t)\right) \\
& =\nabla \cdot\left(\rho(\boldsymbol{x}, t) f(\boldsymbol{x}, t) D_{1} \nabla C_{1}(\boldsymbol{x}, t)\right), \quad \boldsymbol{x} \in \Omega
\end{aligned}
$$


Stabilized finite element models have been increasingly used in the recent years to model fluid flow and solidification problems. In Refs. [14-16], Tezduyar et al. used SUPG-PSPG based finite element methods to model fluid flow. In [17], Sampath and Zabaras used the SUPG-PSPG method to model fluid flow in complex solidification problems. In [18], the authors extended a stabilized finite element model, previously developed in [19], to simulate alloy solidification problems where fluid flow was driven by the combined influence of buoyancy and shrinkage and the mushy zone permeability was either isotropic or anisotropic. Our main objective here is to model horizontal and vertical solidification of an Aluminum-Copper alloy on uneven surfaces using stabilized finite element methods. Surfaces from where solidification initiates are modeled as sinusoids characterized by an amplitude, $A$ and wavelength, $\lambda$. Changes in surface topography are accomplished by varying amplitudes and wavelengths. Therefore, changes in heat transfer, fluid flow, macrosegregation and inverse segregation, arising due to changes in surface topography, are studied and quantified for few limited cases.

The organization of the paper is as follows. In Section 2, the mathematical model along with governing transport equations are discussed in brief. Derivation and details of the volume averaged model, discussed elsewhere, are omitted here. This is followed by the section on numerical examples. First, vertical solidification of an Aluminum-Copper alloy from sinusoidal surfaces is simulated. Inverse segregation is observed in all these examples. The effect of varying surface topography on inverse segregation that occurs at the bottom of the cavity is studied and quantified for few amplitude-wavelength combinations. Variation in midplane solute concentration profiles and vertical velocities are observed with changing surface topography. Next, horizontal solidification of the same alloy in cavities, one of whose sides is sinusoidal, is simulated. Here, convection caused by thermal and solutal buoyancy dominates and shrinkage driven flow is neglected by assuming densities of both phases to be equal. In this case, fluid flow affects solute redistribution significantly and causes macrosegregation in the cavity. Changes in surface topography induce changes in heat transfer rate that affects processes like phase change and convection in the cavity. The resulting variation in macrosegregation with wavelength and amplitude is studied by using specific quantitative measures described in Section 3. Finally, important observations and conclusions drawn from the current analysis are summarized in Section 4.

\section{Mathematical model}

A single domain model based on volume averaged governing transport equations is used for modeling solidification of alloys on uneven surfaces. The model, used here, was derived in [20] from individual microscopic transport equations and is very similar to continuum solidification models discussed in [21-24]. The governing equations are derived by volume averaging the microscopic transport equations of each phase and are listed in Box I. Some of the important assumptions invoked in the model are:

- The solid phase is stationary.

- The flow is Newtonian and laminar.

- Thermal properties are constant and do not vary with temperature.

- The densities of the solid and liquid phases are con- 192 stant (may be different) except in the buoyancy term 193 in the momentum equation due to Boussinesq 194 approximation.

- There is conservation of mass and volume and no 196 pore formation occurs in the domain.

- Air gap formation is not modeled and perfect contact 198 between the mold and metal is assumed at all times. 199

- Local equilibrium is assumed and linearized phase 200 diagram along with lever rule is used in the mushy 201 zone.

Details of the mathematical model, given in [20-22], and description of the numerical scheme, given in $[18,19]$, and are not repeated here. The mushy zone permeability is assumed to be isotropic for all problems solved here and is given by the Kozeny-Carman relation as:

$$
K(\epsilon)=\frac{K_{0} \epsilon^{3}}{(1-\epsilon)^{2}}
$$

where $\epsilon$ denotes the volume fraction of liquid. $K_{0}$ is related to the secondary dendrite arm spacing, $d$, as $K_{0}=d^{2} / 180$. The density in the mushy zone is given by

$\rho=\rho_{1} \epsilon+\rho_{\mathrm{s}}(1-\epsilon)$

where $\rho_{\mathrm{s}}$ and $\rho_{1}$ denote densities of solid and liquid phases, respectively. When the individual phase densities are taken to be equal, shrinkage driven flow does not arise and thermosolutal buoyancy is the only driving force in the fluid flow problem. Stabilized finite element solution methodologies are used for discretizing fluid flow, heat and solute equations. The stabilized finite element method for discretizing the fluid flow problem in alloy solidification systems was previously developed in [19]. In [18], the authors extended the previously developed model to include the effects of shrinkage and anisotropic permeability in the mushy zone while solving the fluid flow problem. Stabilizing terms and parameters were developed in a more general framework in [18] to incorporate effects of different phase densities and different types of mushy zone permeability expressions. The 
233 formulation developed is suited for a wide class of prob-

234 lems. Solidification of Lead-Tin alloys was modeled to

235 study the combined effects of shrinkage and buoyancy

236 driven flow on macrosegregation. Results obtained were

237 compared with those obtained for a similar problem dis-

238 cussed in [25]. The stabilized finite element methodology

239 developed in [18] is therefore used in all the numerical

240 studies here. Thermal and solute species governing equa-

241 tions are discretized by SUPG based finite element method.

242 Closure of the model is obtained using a linear phase

243 diagram shown in Fig. 3 and thermodynamic relation-

244 ships for the two phase region, which are listed below:

245

$h=h_{\mathrm{l}} f+h_{\mathrm{s}}(1-f)$

$C=C_{\mathrm{l}} f+C_{\mathrm{s}}(1-f)$

$f=1-\frac{1}{1-\kappa} \frac{T-T_{\mathrm{liq}}}{T-T_{\mathrm{m}}}$

$C_{1}=\frac{T-T_{\mathrm{m}}}{m_{\mathrm{liq}}}$

$C_{\mathrm{s}}=\kappa C_{\mathrm{l}}$

$\kappa=m_{\text {liq }} / m_{\text {sol }}$

248 where $h_{1}$ and $h_{\mathrm{s}}$ denote the solid and liquid phase enthal-

249 pies given by

$h_{\mathrm{s}}=c_{\mathrm{s}} T$

$260 \epsilon=\frac{\rho f}{\rho_{1}}$

261 Due to conservation of both mass and volume, the solid

respectively.

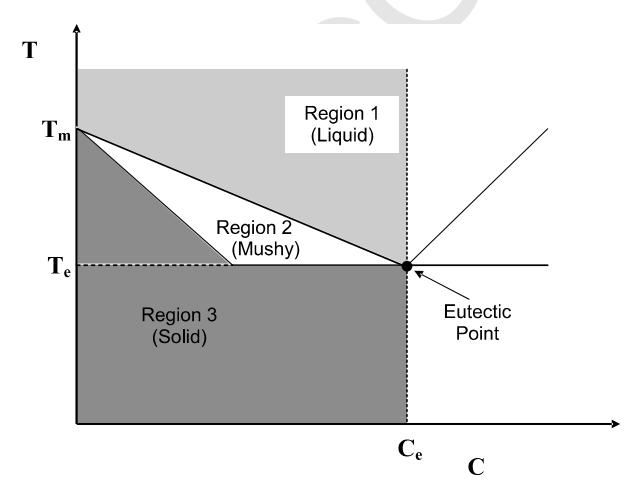

Fig. 3. The phase diagram for $\mathrm{Al}-\mathrm{Cu}$ binary alloy. Individual values are given in Table 1.
The multistep predictor-corrector scheme is used for 264 thermal and solute problems, while the Newton-Raph- 265 son scheme along with a global line search method is 266 used for the fluid flow problem. Linear systems arising 267 from finite element discretization of governing equations 268 are solved by the parallel matrix free GMRES solver. 269 This eliminates the need to assemble global matrices 270 and significantly speeds up the solution process. The 271 reader is referred to $[18,19]$ for details of the transient 272 solution methodology.

\section{3}

\section{Numerical examples}

Solidification of an Aluminum-Copper alloy is simulated in cavities, one of whose surfaces is in the form of sinusoids characterized by an amplitude, $A$ and wavelength, $\lambda$. As mentioned previously, heat is removed from this boundary by convection. Our main emphasis is on the early stages of solidification and events near this boundary which influence phenomenon occurring in the whole domain. The simulations are carried out in both vertical and horizontal configurations and the respective problem domains are shown in Fig. 4. The finite element mesh is constructed from bilinear quadrilateral elements for all examples that will be discussed in the following sections. The depth of the sinusoids is $2 A$. For both horizontal and vertical solidification examples, the initial melt temperature, $T_{\mathrm{i}}$, is taken to be $660^{\circ} \mathrm{C}$. The projected length of the sinusoidal side, $L_{\mathrm{s}}$, is determined from the length of the straight line joining the two end points of the sinusoidal side.

275 276 277 278 279 280 281 282 283 284 285 286 287 288 289 290 291 292

\subsection{Vertical solidification of an Aluminum-Copper alloy}

Vertical solidification of an Aluminum-Copper alloy is simulated in a cavity with a sinusoidal bottom surface. The problem domain along with the boundary condi-

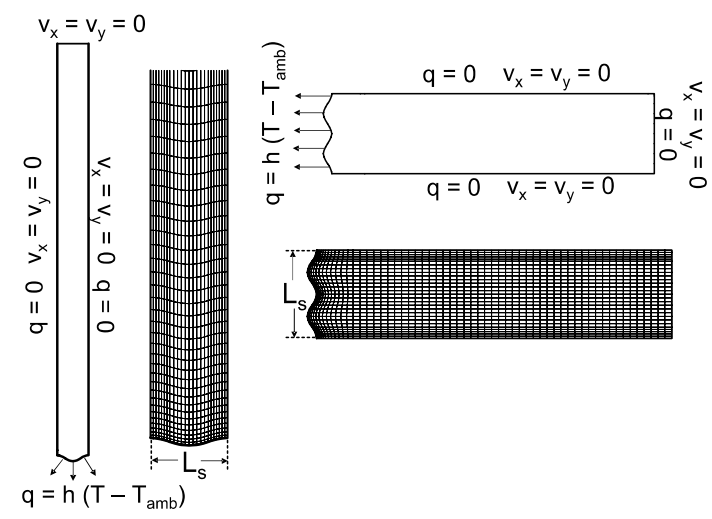

Fig. 4. Domain and the mesh for the solidification of Aluminum alloy. 
298 tions is shown in Fig. 4. No slip conditions are assumed

299 on all boundaries. Heat is removed from the sinusoidal

300 boundary by convection. The projected length, $L_{\mathrm{s}}$, of

301 the sinusoidal boundary is taken as $0.01 \mathrm{~m}$ for all exam-

302 ples in this section. The finite element mesh near this

303 boundary is skewed slightly because of the presence of

304 higher thermal gradients. Important physical parameters

305 for all examples in this section are summarized in Table

306 1. The composition of the alloy under consideration is

$3074.1 \%$ Copper and rest Aluminum. This alloy is charac-

308 terized by a wide freezing range of about $68{ }^{\circ} \mathrm{C}$ and con-

309 sequently a wide mushy zone. The vertical dimension of

310 the cavity is assumed to be long enough to prevent the

311 mushy zone from reaching the top surface. The volume

312 change arising due to different densities of solid and li-

313 quid phases is compensated by moving the top surface

314 downwards like a rigid lid. The rate at which the lid

315 moves downward is calculated from the volume change

316 and this procedure has been discussed originally in [10].

317 The main aim here is to study variation in fluid flow and

318 inverse segregation due to varying mold topography. In-

319 verse segregation, usually found in vertically solidified

320 castings, is caused primarily by shrinkage driven flow.

321 The change in surface topography is accomplished by

322 first varying amplitudes of the surfaces from $0.25 \mathrm{~mm}$ to $1 \mathrm{~mm}$, keeping the wavelength constant at $10 \mathrm{~mm}$, and then varying the wavelengths from $2.5 \mathrm{~mm}$ to $10 \mathrm{~mm}$ keeping the amplitude constant at $0.5 \mathrm{~mm}$.

For each amplitude-wavelength $(A-\lambda)$ combination, evolution of the two-phase mushy zone and solid along with the solute distribution and fluid flow are studied. The reference problem consists of solidification of the
Table 1

Important physical parameters for Aluminum-Copper alloy

\begin{tabular}{lll}
\hline Symbol & Value & Units \\
\hline$k_{\mathrm{s}}$ & 0.19249 & $\mathrm{~kW} \mathrm{~m}^{-1}{ }^{\circ} \mathrm{C}^{-1}$ \\
$k_{\mathrm{l}}$ & 0.08261 & $\mathrm{~kW} \mathrm{~m}^{-1}{ }^{\circ} \mathrm{C}^{-1}$ \\
$c_{\mathrm{S}}$ & 1.0928 & $\mathrm{~kJ} \mathrm{~kg}^{-1}{ }^{\circ} \mathrm{C}^{-1}$ \\
$c_{\mathrm{l}}$ & 1.0588 & $\mathrm{~kJ} \mathrm{~kg}^{-1}{ }^{\circ} \mathrm{C}^{-1}$ \\
$h_{\mathrm{f}}$ & 397.5 & $\mathrm{~kJ} \mathrm{~kg}^{-1}$ \\
$\kappa$ & 0.17 & \\
$\beta_{\mathrm{T}}$ & $4.95 \times 10^{-5}$ & ${ }^{\circ} \mathrm{C}^{-1}$ \\
$\beta_{\mathrm{S}}$ & -2.0 & \\
$\rho_{\mathrm{s}}$ & 2650 & $\mathrm{~kg} \mathrm{~m}^{-3}$ \\
$\rho_{\mathrm{l}}$ & 2400 & $\mathrm{~kg} \mathrm{~m}^{-3}$ \\
$\mu$ & 0.003 & $\mathrm{~kg} \mathrm{~m}^{-1} \mathrm{~s}^{-1}$ \\
$T_{\mathrm{e}}$ & 548.0 & ${ }^{\circ} \mathrm{C}$ \\
$T_{\mathrm{m}}$ & 660.0 & ${ }^{\circ} \mathrm{C}$ \\
$T_{\mathrm{i}}$ & 660.0 & ${ }^{\circ} \mathrm{C}$ \\
$T_{\text {amb }}$ & 20.0 & ${ }^{\circ} \mathrm{C}$ \\
$C_{\mathrm{l}, 0}$ & 0.041 & \\
$C_{\mathrm{e}}$ & 0.332 & \\
$g$ & 9.81 & $\mathrm{~ms}^{-2}$ \\
$m_{\text {liq }}$ & -337.35 & ${ }^{\circ} \mathrm{C}$ \\
$D_{\mathrm{l}}$ & $3 \times 10^{-9}$ & $\mathrm{~m}^{2} \mathrm{~s}^{-1}$ \\
$h_{\text {conv }}$ & 1.0 & $\mathrm{~kW} \mathrm{~m}^{-2}{ }^{\circ} \mathrm{C}^{-1}$ \\
\hline
\end{tabular}

same alloy in a perfectly rectangular cavity. Amplitude 330 and wavelength for this case are taken as 0 and $\infty, 331$ respectively. Figs. 5, 6 and 8 show the isotherms, liquid 332 mass fraction and liquid solute concentrations at two 333 different times $\left(t_{1}=66 \mathrm{~s}\right.$ and $\left.t_{2}=121 \mathrm{~s}\right)$ for few $A-\lambda 334$ combinations. Fig. 9 shows same quantities for the ref- 335 erence problem. During the early stages, some distor- 336 tions in the solid shell are observed. With progressive 337

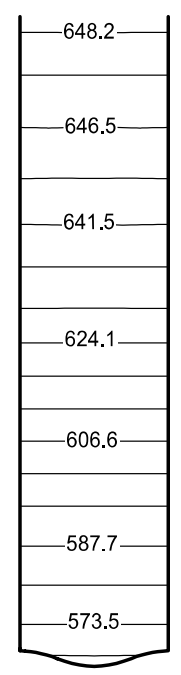

(a)

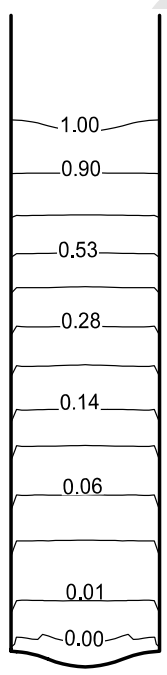

(b)

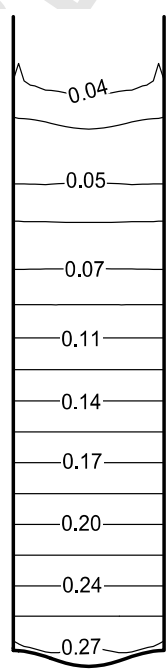

(c)

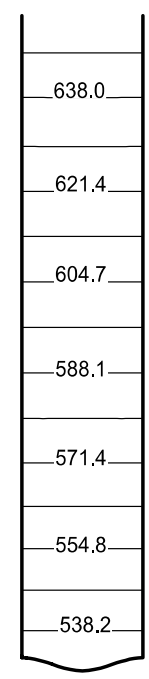

(a)

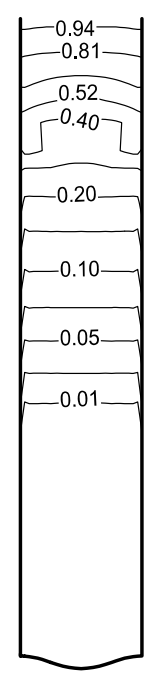

(b)

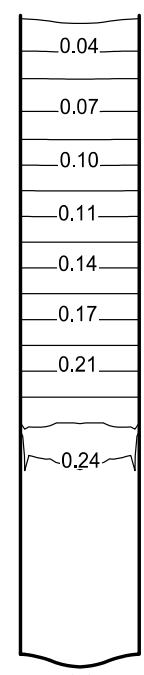

(c)

$$
t=t_{1}
$$

Fig. 5. (a) Isotherms, (b) liquid volume fraction, and (c) liquid concentration lines at $t_{1}=66 \mathrm{~s}$ and $t_{2}=121 \mathrm{~s}$ for solidification with shrinkage in Section $3.1(\lambda=10 \mathrm{~mm}, A=0.5 \mathrm{~mm})$. 


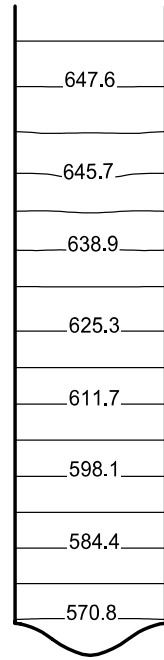

(a)

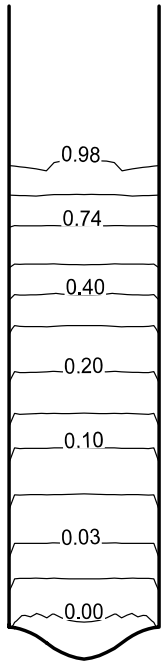

(b)

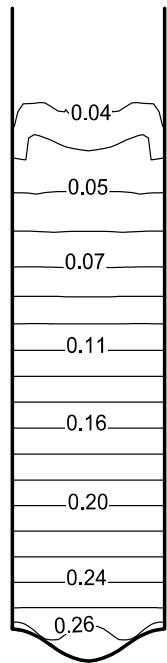

(c)

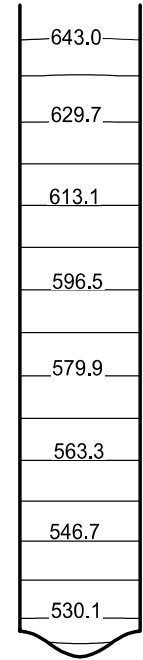

(a)

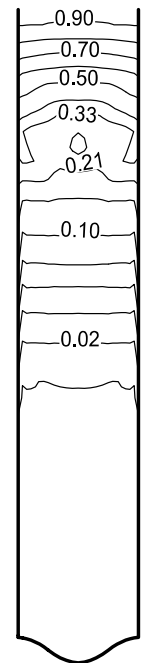

(b)

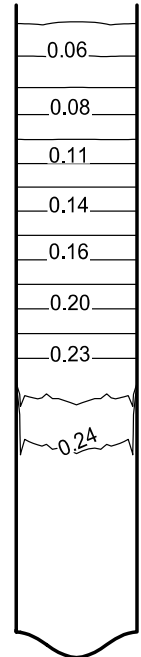

(c)

$t=t_{1}$

Fig. 6. (a) Isotherms, (b) liquid volume fraction, and (c) liquid concentration lines at $t_{1}=66 \mathrm{~s}$ and $t_{2}=121 \mathrm{~s}$ for solidification with shrinkage in Section $3.1(\lambda=10 \mathrm{~mm}, A=1 \mathrm{~mm})$.
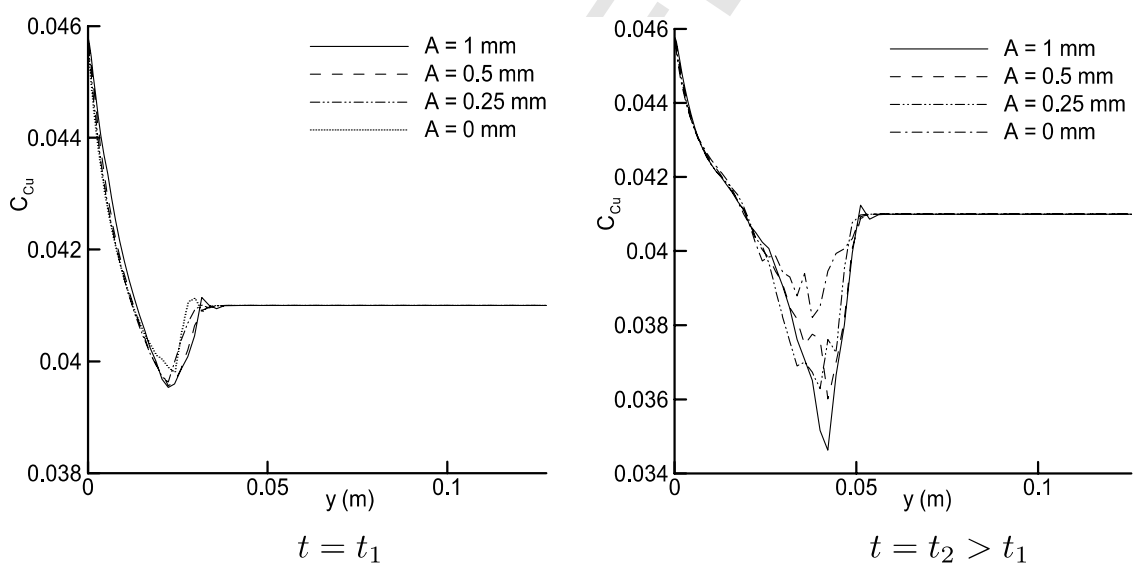

Fig. 7. Midplane $(x=0.005 \mathrm{~m})$ solute concentration profiles at $t_{1}=66 \mathrm{~s}$ and $t_{2}=121 \mathrm{~s}$ for different amplitudes at a fixed wavelength for solidification with shrinkage in Section $3.1(\lambda=10 \mathrm{~mm})$.

solidification these distortions disappear. Fluid flow in all these cases is driven by a combination of buoyancy and shrinkage. Figs. 7 and 10 summarize midplane ( $x=0.005 \mathrm{~m}$ or mid-point of a trough) concentrations of $\mathrm{Cu}$ for varying amplitudes and wavelengths, respectively. Both these figures clearly reveal a zone of positive segregation near the bottom of the cavity followed by a zone of negative segregation. This is known as the inverse segregation phenomenon. From Fig. 7, it is observed that at constant wavelength the degree of midplane segregation, defined as the difference between the maximum and minimum midplane solute concentra- 349 tions, increases with increasing amplitude. Similarly, 350 from Fig. 10, it is evident that at constant amplitude 351 the degree of segregation increases with decreasing 352 wavelength. The zone of negative segregation clearly 353 magnifies with increasing amplitude or decreasing wave- 354 length. Similar trends are observed for maximum veloc- 355 ity magnitudes, $|v|_{\max }$, listed in Tables 2 and 3 at a 356 particular time for increasing amplitudes and wave- 357 lengths, respectively. $|v|_{\max }$ increases with either increas- 358 ing amplitudes at constant wavelength or decreasing 359 


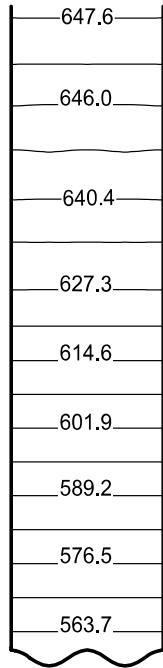

(a)

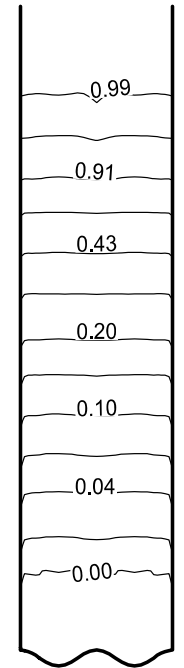

(b)

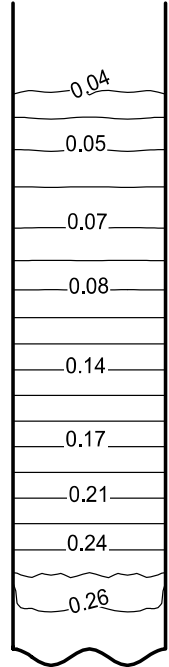

(c)

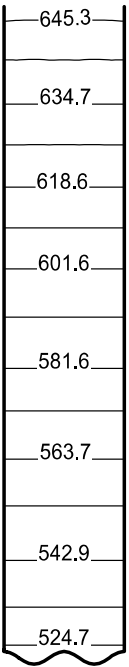

(a)

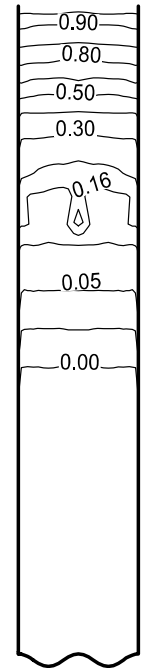

(b)

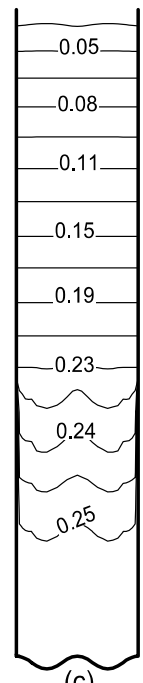

(c)

$t=t_{1}$

$t=t_{2}>t_{1}$

Fig. 8. (a) Isotherms, (b) liquid volume fraction, and (c) liquid concentration lines at $t_{1}=66 \mathrm{~s}$ and $t_{2}=121 \mathrm{~s}$ for solidification with shrinkage in Section $3.1(\lambda=5 \mathrm{~mm}, A=0.5 \mathrm{~mm})$.

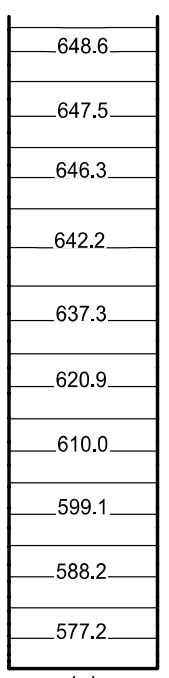

(a)

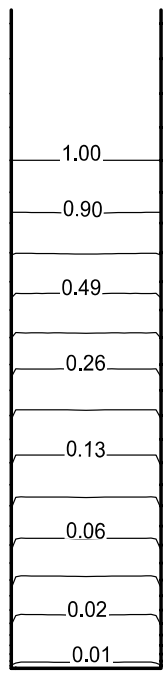

(b)

$t=t_{1}$

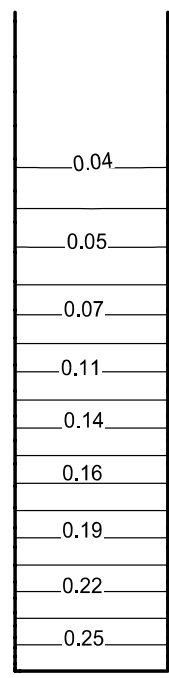

(c)

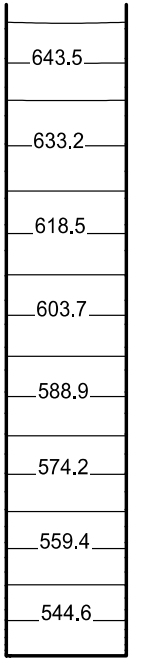

(a)

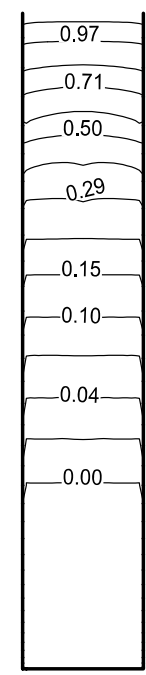

(b)

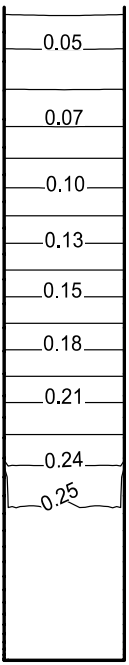

(c)

$t=t_{2}>t_{1}$

Fig. 9. (a) Isotherms, (b) liquid volume fraction, and (c) liquid concentration lines at $t_{1}=66 \mathrm{~s}$ and $t_{2}=121 \mathrm{~s}$ for solidification with shrinkage in Section $3.1(\lambda=\infty, A=0$, perfectly rectangular cavity).

360 wavelength at a constant amplitude. Fig. 14 shows the 361 vertical midplane velocities, $v_{y}$, at a particular time for 362 increasing amplitude and wavelength. Here too, like in 363 the previous cases, $v_{y}$ magnitudes are higher for smaller 364 wavelengths and larger amplitudes. Difference between 365 maximum and minimum solute concentrations, $\Delta C$, 366 for varying amplitudes and wavelengths are given in
Tables 4 and 5, respectively. $\Delta C$ shows the same behav- 367 ior as $|v|_{\max }$ for varying surface topography. All these 368 observations can be attributed to the fact that with 369 increasing amplitude or decreasing wavelength, contact 370 surface area between the mold and the solidifying metal 371 increases. This increases the heat transfer rate which in 372 turn enhances the fluid flow in the melt. Fluid flow 373 

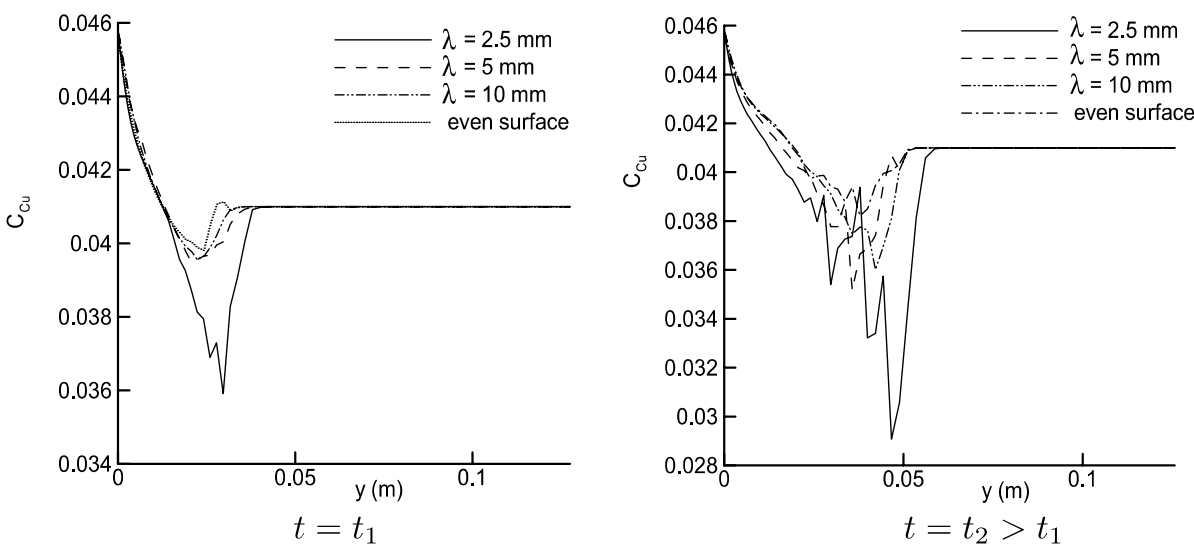

Fig. 10. Midplane $(x=0.005 \mathrm{~m})$ solute concentration profiles at $t_{1}=66 \mathrm{~s}$ and $t_{2}=121 \mathrm{~s}$ for different wavelengths at a fixed amplitude for solidification with shrinkage in Section $3.1(A=0.5 \mathrm{~mm})$.

Table 2

Maximum velocity magnitudes $\left(\left|v_{\max }\right|\right)$, at $t=84 \mathrm{~s}$ with varying amplitudes and constant wavelength in Section $3.1(\lambda=10 \mathrm{~mm})$

\begin{tabular}{ll}
\hline Amplitude $(\mathrm{mm})$ & $\left|v_{\max }\right|(\mathrm{mm} / \mathrm{s})$ \\
\hline 0.0 & 0.536 \\
0.25 & 0.570 \\
0.5 & 0.571 \\
1.0 & 0.629 \\
\hline
\end{tabular}

Table 3

Maximum velocity magnitudes $\left(\left|v_{\max }\right|\right)$, at $t=84 \mathrm{~s}$ with varying wavelengths and constant amplitude in Section 3.1 $(A=0.5 \mathrm{~mm})$

\begin{tabular}{ll}
\hline Wavelength $(\mathrm{mm} / \mathrm{s})$ & $\left|v_{\max }\right|(\mathrm{mm} / \mathrm{s})$ \\
\hline 2.5 & 0.729 \\
5 & 0.678 \\
10 & 0.570 \\
$\infty$ & 0.536 \\
\hline
\end{tabular}

enhances solute redistribution through convection and this contributes to higher segregation when amplitudes are increased or wavelengths reduced. Due to the higher rate of heat removal, the amount of solid formed at a given time is higher for a bigger amplitude and smaller wavelength. This is clearly evident after comparing Figs. $5 \mathrm{~b}, 6 \mathrm{~b}, 8 \mathrm{~b}$ and $9 \mathrm{~b}$. For the reference case at time $t=t_{1}$, the amount of solid formed is almost negligible when compared with other cases.

To examine the role of shrinkage driven flow in inverse segregation, some of these examples were repeated after assuming phase densities of solid and liquid to be equal. In this case, the driving force was thermal and solutal buoyancy and shrinkage driven flow was absent. Figs. 11 and 12 show the isotherms, liquid mass frac- tions and liquid solute concentrations for both these cases. Fig. 13 shows the midplane concentration of $\mathrm{Cu}$ for two wavelengths. From Fig. 13, it is evident that inverse segregation is practically negligible and solute distribution is far lower than in the preceding cases involving shrinkage driven flow. This establishes the importance of shrinkage driven flow in causing inverse segregation in castings solidified vertically from below.

\subsection{Horizontal solidification of an Aluminum-Copper alloy}

Solidification of the same alloy in a horizontal cavity, one of whose sides is of sinusoidal shape, is simulated here. The effect of shrinkage driven flow is neglected here due to the dominance of thermosolutal buoyancy driven flows. Important physical properties are summarized in Table 1 and the density is taken as an average of solid and liquid densities. Fig. 4 shows the problem domain and the boundary conditions. The projected length, $L_{\mathrm{s}}$, of the sinusoidal surface is taken to be $0.02 \mathrm{~m}$ for all numerical studies reported here. Heat is removed from the uneven boundary through convection. The finite element mesh is skewed near this boundary similar to that in the vertical solidification examples. The reference case here corresponds to the example where solidification occurs in a perfectly rectangular cavity with same dimensions as the uneven cavities. Fluid flow, driven by thermal and solutal buoyancy, leads to redistribution of solute in the cavity. In this example both thermal and solutal buoyancy aid each other. Solute depletion occurs prominently at the top left half of the cavity and solute enrichment at the left bottom half. Segregated zones increase in size rightwards as solidification progresses. Figs. 15(b)-20(b) illustrate 


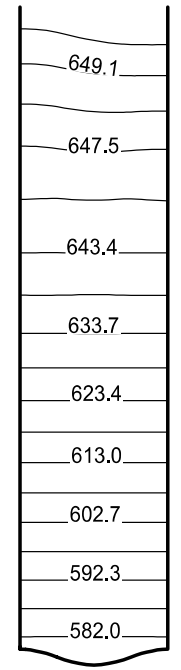

(a)

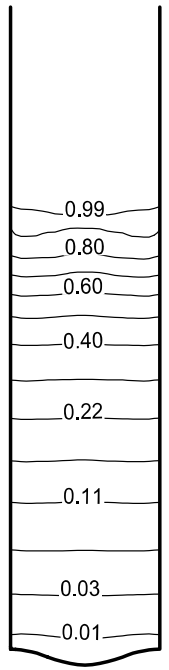

(b)

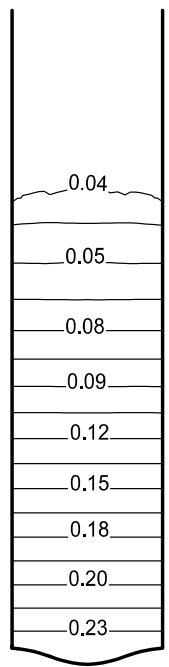

(c)

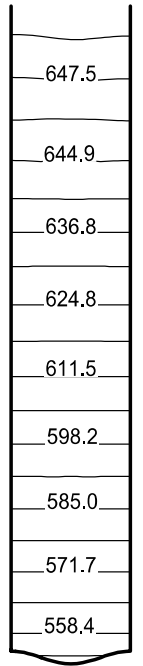

(a)

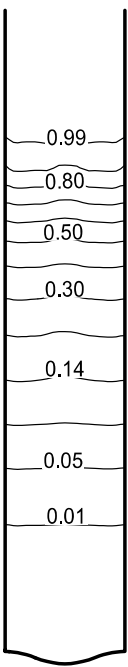

(b)

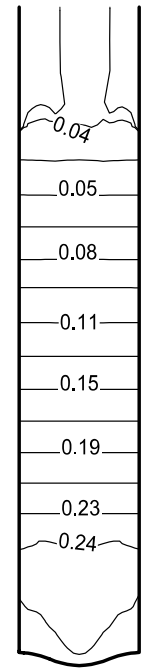

(c)

$t=t_{1}$

Fig. 11. (a) Isotherms, (b) liquid volume fraction, and (c) liquid concentration lines at $t_{1}=66 \mathrm{~s}$ and $t_{2}=121 \mathrm{~s}$ for solidification without shrinkage in Section $3.1(\lambda=10 \mathrm{~mm}, A=0.5 \mathrm{~mm})$.

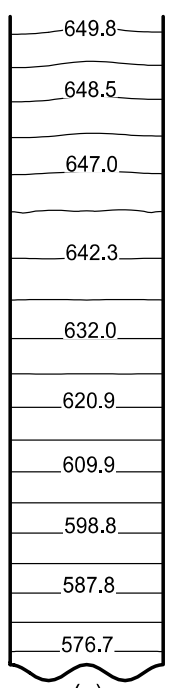

(a)

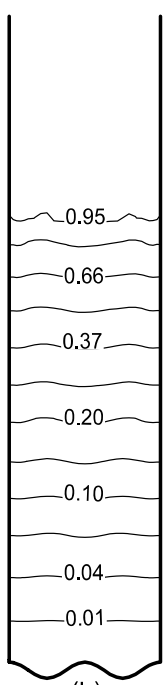

(b)

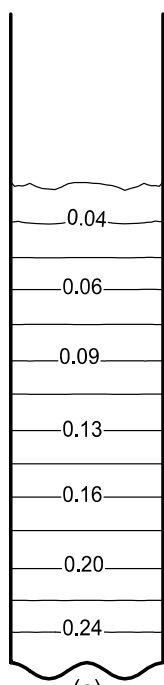

(c)

$$
t=t_{1}
$$

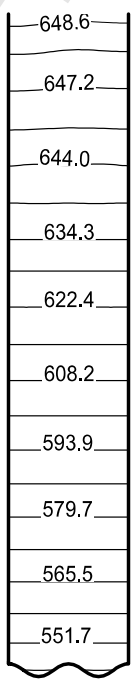

(a)

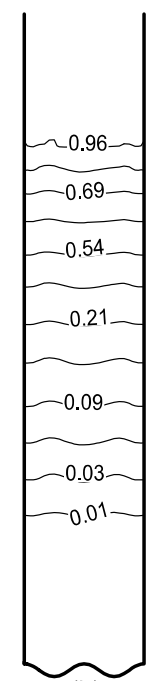

(b)

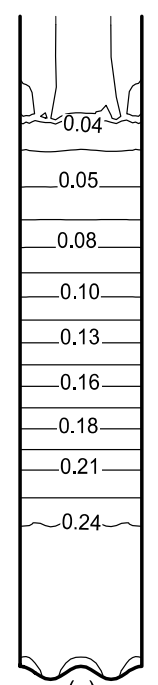

(c) $t=t_{2}>t_{1}$

Fig. 12. (a) Isotherms, (b) liquid volume fraction, and (c) liquid concentration lines at $t_{1}=66 \mathrm{~s}$ and $t_{2}=121 \mathrm{~s}$ for solidification without shrinkage in Section $3.1(\lambda=5 \mathrm{~mm}, A=0.5 \mathrm{~mm})$.

422 this effectively for few $A-\lambda$ combinations at times $423 t_{1}=66 \mathrm{~s}$ and $t_{2}=121 \mathrm{~s}$. Isotherms, liquid solute concen424 trations and liquid mass fractions for the corresponding 425 cases are summarized in Figs. 15(a), (c) and (d)-20(a), 426 (c) and (d), respectively. Effect of convection, much 427 stronger here than in the vertical solidification examples, is clearly evident in these fields which are distorted. Var- 428 iation in macrosegregation caused by changes in surface 429 topography is measured by the global extent of segrega- 430 tion (GES) and difference between the maximum and 431 minimum solute concentrations, $\Delta C$. GES is defined 432 using nodal variables as follows: 

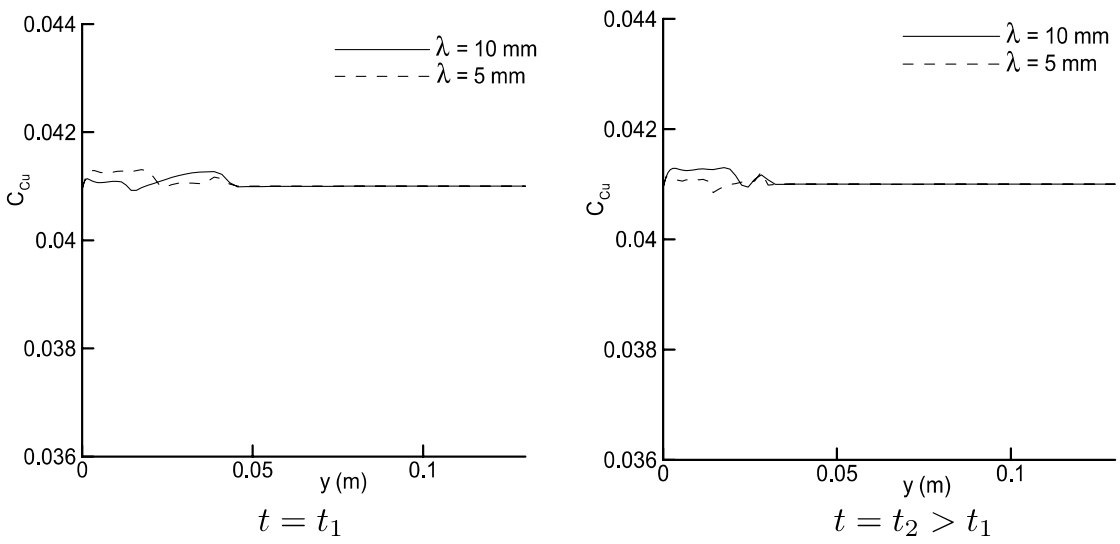

Fig. 13. Midplane $(x=0.005 \mathrm{~m})$ solute concentration profiles at $t_{1}=66 \mathrm{~s}$ and $t_{2}=121 \mathrm{~s}$ for different wavelengths at a fixed amplitude for solidification without shrinkage in Section $3.1(A=0.5 \mathrm{~mm})$.
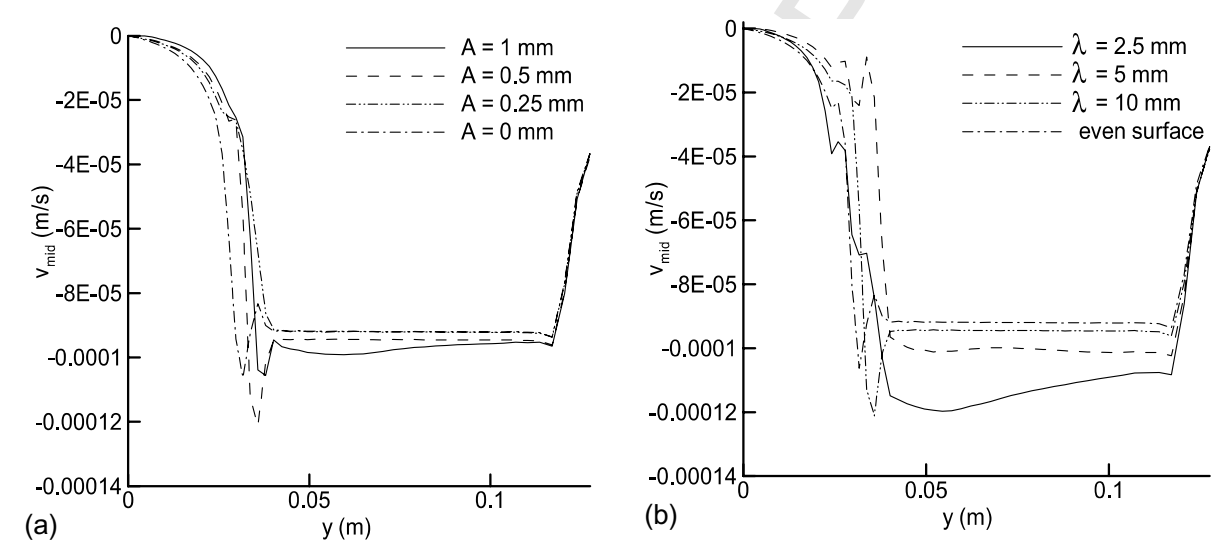

Fig. 14. Midplane vertical velocities, $v_{y}$, at $t=66 \mathrm{~s}$ for solidification with shrinkage in Section 3.1: (a) varying amplitudes $(\lambda=10 \mathrm{~mm})$, (b) varying wavelengths $(A=0.5 \mathrm{~mm})$.

Table 4

Difference between maximum and minimum solute concentrations $(\Delta C)$, at $t=84 \mathrm{~s}$ with varying amplitudes and constant wavelength in Section $3.1(\lambda=10 \mathrm{~mm})$

\begin{tabular}{ll}
\hline Amplitude $(\mathrm{mm})$ & $\Delta C(\mathrm{wt} . \% \mathrm{Cu})$ \\
\hline 0 & 0.561 \\
0.25 & 0.623 \\
0.5 & 0.624 \\
1.0 & 0.640 \\
\hline
\end{tabular}

$\mathrm{GES}=\frac{100}{C_{0}}\left(\sum_{j=1}^{N}\left(C_{j}-C_{0}\right)^{2} / N\right)^{1 / 2}$

436 where $N$ denotes the number of nodal points in the domain. Tables 6 and 9 show GES and $\Delta C$ with varying amplitudes and fixed wavelength at $t=120 \mathrm{~s}$. Tables 7
Table 5

Difference between maximum and minimum solute concentrations $(\Delta C)$, at $t=84 \mathrm{~s}$ with varying wavelengths and constant amplitude in Section $3.1(A=0.5 \mathrm{~mm})$

\begin{tabular}{ll}
\hline Wavelength $(\mathrm{mm})$ & $\Delta C($ wt. $\% \mathrm{Cu})$ \\
\hline 2.5 & 2.096 \\
5.0 & 0.628 \\
10.0 & 0.624 \\
$\infty$ & 0.561 \\
\hline
\end{tabular}

and 10 show the same quantities for varying wavelength and fixed amplitude at $t=120 \mathrm{~s}$. From these tables one can observe that at fixed wavelength, higher the amplitude, greater is the extent of segregation. This means that there are more points in the domain where the concentration is different from the initial value. This can be attributed to higher heat transfer rates that increase fluid 


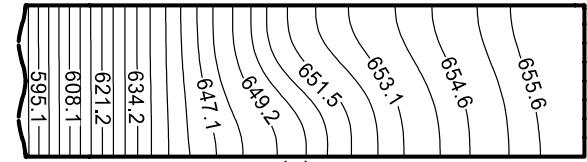

(a)
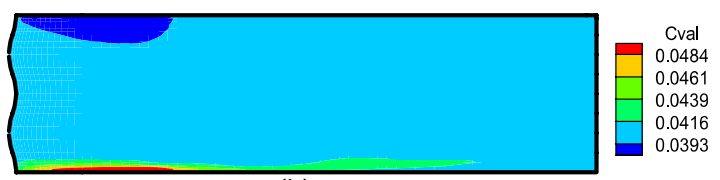

(b)

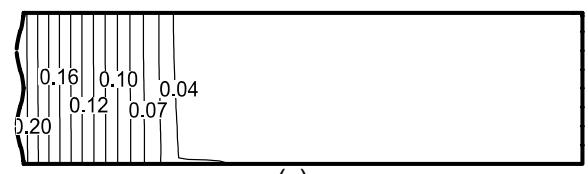

(c)

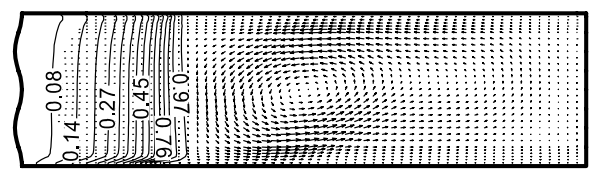

(d)

Fig. 15. (a) Isotherms, (b) solute concentration distribution, (c) liquid solute concentration, and (d) liquid volume fraction and velocity distribution at time $t=66 \mathrm{~s}$ in Section 3.2 with $\lambda=10 \mathrm{~mm}$ and $A=0.5 \mathrm{~mm}$.

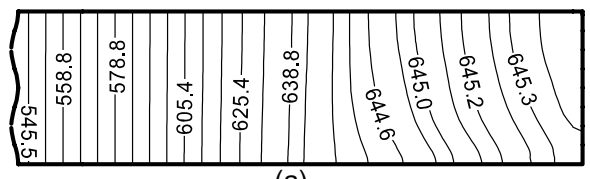

(a)

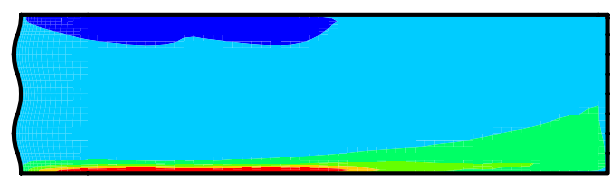

(b)

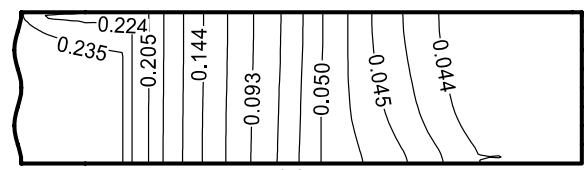

(c)

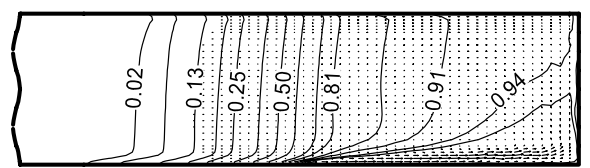

(d)

Fig. 16. (a) Isotherms, (b) solute concentration distribution, (c) liquid solute concentration, and (d) liquid volume fraction and velocity distribution at time $t=121 \mathrm{~s}$ in Section 3.2 with $\lambda=10 \mathrm{~mm}$ and $A=0.5 \mathrm{~mm}$.

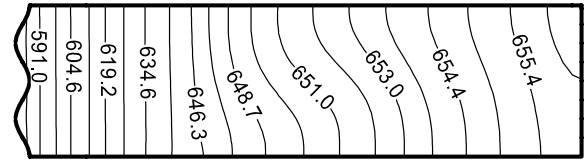

(a)

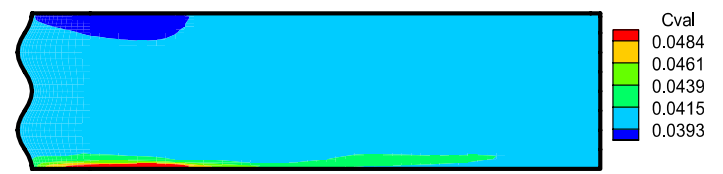

(b)

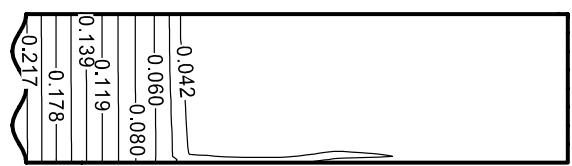

(c)

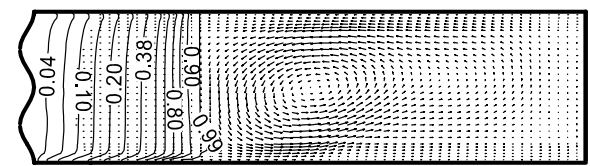

(d)

Fig. 17. (a) Isotherms, (b) solute concentration distribution, (c) liquid solute concentration, and (d) liquid volume fraction and velocity distribution at time $t=66 \mathrm{~s}$ in Section 3.2 with $\lambda=10 \mathrm{~mm}$ and $A=1 \mathrm{~mm}$.

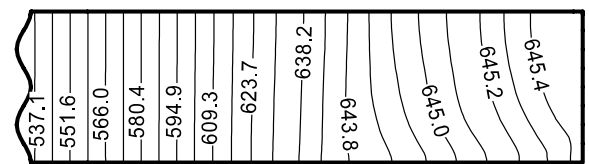

(a)

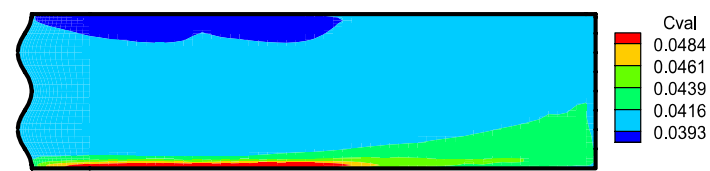

(b)

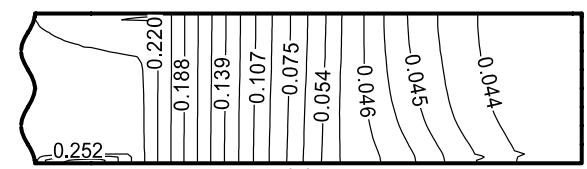

(c)

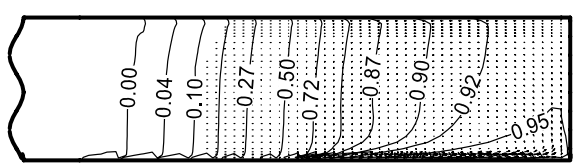

(d)

Fig. 18. (a) Isotherms, (b) solute concentration distribution, (c) liquid solute concentration, and (d) liquid volume fraction and velocity distribution at time $t=121 \mathrm{~s}$ in Section 3.2 with $\lambda=10 \mathrm{~mm}$ and $A=1 \mathrm{~mm}$. 


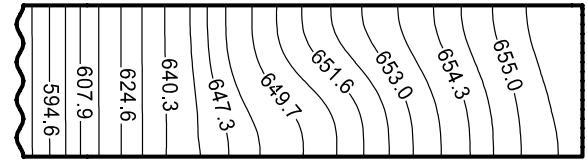

(a)

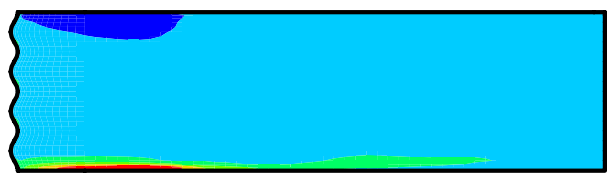
Cval 0.0484 0.0461 0.0439 0.0415

(b)

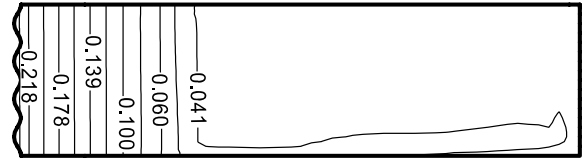

(c)

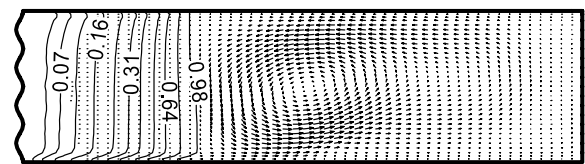

(d)

Fig. 19. (a) Isotherms, (b) solute concentration distribution, (c) liquid solute concentration, and (d) liquid volume fraction and velocity distribution at time $t=66 \mathrm{~s}$ in Section 3.2 with $\lambda=5 \mathrm{~mm}$ and $A=0.5 \mathrm{~mm}$.

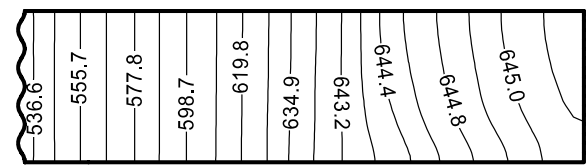

(a)
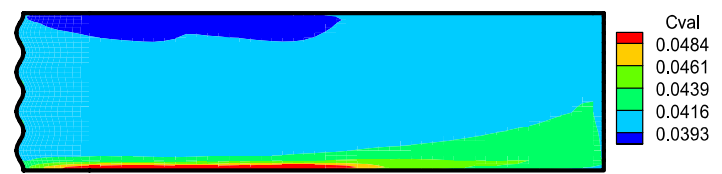

(b)

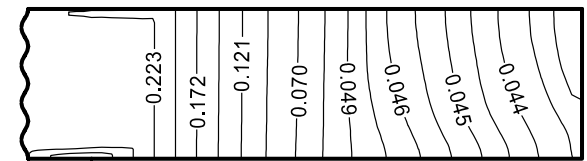

(c)

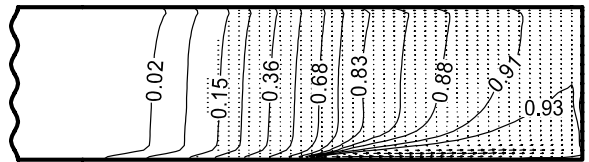

(d)

Fig. 20. (a) Isotherms, (b) solute concentration distribution, (c) liquid solute concentration, and (d) liquid volume fraction and velocity distribution at time $t=121 \mathrm{~s}$ in Section 3.2 with $\lambda=5 \mathrm{~mm}$ and $A=0.5 \mathrm{~mm}$.
Table 6

Comparison of GES with varying amplitudes in Section 3.2 $(\lambda=10 \mathrm{~mm})$

\begin{tabular}{ll}
\hline Amplitude $(\mathrm{mm})$ & GES $(\%)(t=120 \mathrm{~s})$ \\
\hline 0.0 & 1.006 \\
0.25 & 1.619 \\
0.5 & 1.903 \\
1.0 & 2.472 \\
\hline
\end{tabular}

Table 7

Comparison of GES with varying wavelengths in Section 3.2 $(A=0.5 \mathrm{~mm})$

\begin{tabular}{ll}
\hline Wavelength $(\mathrm{mm})$ & $\operatorname{GES}(\%)(t=120 \mathrm{~s})$ \\
\hline 4 & 2.686 \\
5 & 2.650 \\
10.0 & 1.903 \\
$\infty$ & 1.006 \\
\hline
\end{tabular}

Table 8

Maximum GES values for various $A-\lambda$ combinations in Section 3.2

\begin{tabular}{lll}
\hline Amplitude $(\mathrm{mm})$ & Wavelength $(\mathrm{mm})$ & GES $_{\max }(\%)$ \\
\hline 0.0 & $\infty$ & 1.006 \\
0.25 & 10.0 & 1.619 \\
0.5 & 10.0 & 1.903 \\
1.0 & 10.0 & 2.472 \\
0.5 & 5.0 & 2.650 \\
0.5 & 4.0 & 2.686 \\
\hline
\end{tabular}

Table 9

Comparison of $\Delta C$ with varying amplitudes in Section 3.2 $(\lambda=10 \mathrm{~mm})$

\begin{tabular}{ll}
\hline Amplitude $(\mathrm{mm})$ & $\Delta C($ wt. $\% \mathrm{Cu})(t=120 \mathrm{~s})$ \\
\hline 0 & 1.369 \\
0.25 & 1.719 \\
0.5 & 1.592 \\
1.0 & 1.562 \\
\hline
\end{tabular}

Table 10

Comparison of $\Delta C$ with varying wavelengths in Section 3.2 $(A=0.5 \mathrm{~mm})$

\begin{tabular}{ll}
\hline Wavelength $(\mathrm{mm})$ & $\Delta C($ wt. $\% \mathrm{Cu})(t=120 \mathrm{~s})$ \\
\hline 4.0 & 1.389 \\
5.0 & 1.533 \\
10 & 1.592 \\
$\infty$ & 1.369 \\
\hline
\end{tabular}

flow prior to phase change, thereby causing redistribu- 446 tion of solute over a larger area. This in turn is because 447 of larger contact surface areas that magnify heat transfer 448 rates, when surface unevenness increases. 
Table 11

Maximum velocity magnitudes $\left(\left|v_{\max }\right|\right)$ with varying amplitudes at $t=60 \mathrm{~s}$ in Section $3.2(\lambda=10 \mathrm{~mm})$

\begin{tabular}{ll}
\hline Amplitude $(\mathrm{mm})$ & $\left|v_{\max }\right|(\mathrm{mm} / \mathrm{s})$ \\
\hline 0.0 & 6.104 \\
0.25 & 7.633 \\
0.5 & 6.117 \\
1.0 & 6.112 \\
\hline
\end{tabular}

Table 12

Maximum velocity magnitudes $\left(\left|v_{\max }\right|\right)$ with varying wavelengths at $t=60 \mathrm{~s}$ in Section $3.2(A=0.5 \mathrm{~mm})$

\begin{tabular}{ll}
\hline Wavelength $(\mathrm{mm})$ & $\left|v_{\max }\right|(\mathrm{mm} / \mathrm{s})$ \\
\hline 4.0 & 6.033 \\
5.0 & 6.137 \\
10.0 & 6.117 \\
$\infty$ & 6.104 \\
\hline
\end{tabular}

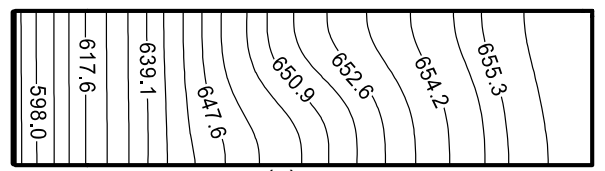

(a)

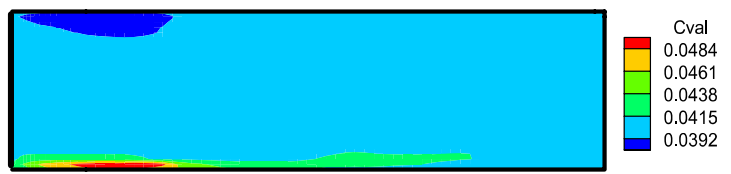

(b)

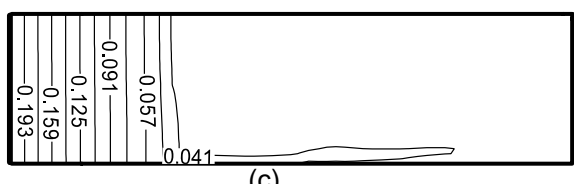

(c)

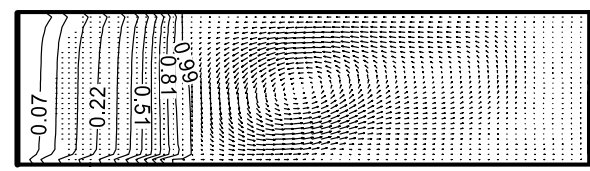

(b)

Fig. 21. (a) Isotherms, (b) solute concentration distribution, (c) liquid solute concentration, and (d) liquid volume fraction and velocity distribution at time $t=66 \mathrm{~s}$ for a horizontal cavity with even left surfaces in Section 3.2.

However, with increasing surface unevenness accomplished either by increasing the amplitude or decreasing the wavelength, $\Delta C$ tends to decrease, barring the reference case. Higher heat transfer rates accelerate the phase

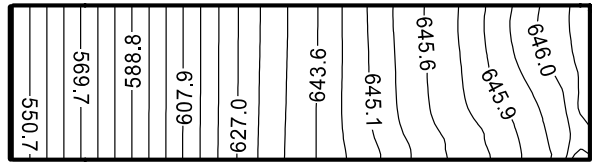

(a)

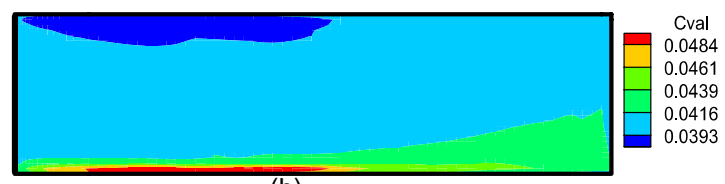

(b)
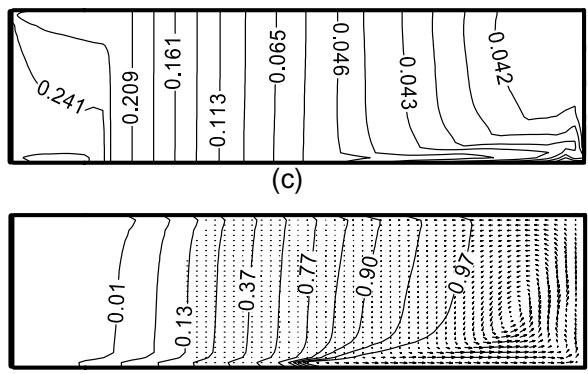

(d)

Fig. 22. (a) Isotherms, (b) solute concentration distribution, (c) liquid solute concentration, and (d) liquid volume fraction and velocity distribution at time $t=121 \mathrm{~s}$ for a horizontal cavity with even left surfaces in Section 3.2.

change process and this leads to suppression of convection, once phase change occurs. Maximum velocity magnitudes shown in Tables 11 and 12 for varying amplitudes and wavelengths, respectively, at a particular time, also emphasize this observation. As a consequence, solute redistribution is relatively inhibited due to increase in surface unevenness, barring the reference case. GES on the other hand indicates the overall extent of macrosegregation. For all cases, GES increases monotonically from the initial stages and reaches a final value beyond which it does not change. This is because, in later stages, convection in the cavity is negligible due to the presence of mushy zone and solid phase. Table 8 shows maximum GES values for different $A-\lambda$ combinations. In the reference example, consisting of horizontal solidification in a perfectly rectangular cavity, the amplitude is taken as 0 and wavelength $\infty$. Figs. 21 and 22 summarize results for this case. Figs. 21(b) and 22(b) show macrosegregation patterns for this example at two different times. They are very similar to those observed previously during solidification from uneven surfaces. From Tables 6 and 7, it is obvious that GES for this case is the lowest in both categories. This implies that under the current assumptions, increasing the surface unevenness in the form of sinusoids increases the overall extent of segregation, while the degree of segregation, $\Delta C$, first increases and then decreases. 


\section{Conclusions}

\section{References}

The effect of surface topography on solidification of an Aluminum-Copper alloy was examined for sinusoidal curves of different wavelengths and amplitudes. The main aim here was to study the effect of uneven surface topography on heat transfer, phase change, fluid flow and macrosegregation in the solidifying alloy. Simulations were carried out in both horizontal and vertical configurations. Inverse segregation was found in all vertical solidification examples and the extent of segregated zones increased with increasing surface unevenness. This was attributed to higher shrinkage driven flows in the mushy zone, due to higher rates of phase change, which in turn was because of increase in contact surface areas between the mold and metal. The growing solid shell is distorted in the vicinity of the sinusoids, but these distortions disappear as solidification progressed. When densities of both solid and liquid phases were equal, inverse segregation was negligible. This was attributed to the absence of shrinkage driven flow in the casting.

During horizontal solidification of the same alloy, convection, driven by thermosolutal buoyancy, was much stronger and the effect of shrinkage was neglected. The extent of macrosegregation increased with increasing surface unevenness. This was because of greater fluid flow prior to phase change, due to increase in surface unevenness. This also led to higher heat transfer rates, which increased phase change rates and consequently suppressed convection, once phase change occurred. As a consequence, the degree of segregation, obtained from the sum of deviations from the initial solute concentration, decreased with increasing surface unevenness, barring the reference case.

The studies reported here may be useful in the design of optimal mold topographies for control of the solid shell growth and microstructure. Dynamic coupling of the simulation tools reported in this work with air-gap modeling is currently in progress.

\section{Acknowledgements}

This work presented here is funded by the Industry Partnerships for Aluminum Industry of the Future Program of the Office of Industrial Technologies of the US Department of Energy (DE-FC07-02ID14396) with additional matching support from Alcoa. This research was conducted using the resources of Cornell Theory Center which receives funding from New York State and other federal agencies.

[1] A. Mo, Mathematical modeling of surface segregation in aluminum DC casting caused by exudation, Int. J. Heat Mass Transfer 36 (18) (1993) 4335-4340.
[2] E. Haug, A. Mo, H.J. Thevik, Macrosegregation near a 532 cast surface caused by exudation and solidification shrink- 533 age, Int. J. Heat Mass Transfer 38 (9) (1995) 1553-1563. 534

[3] K.C. Chiang, H.L. Tsai, Shrinkage induced fluid flow and 535 domain change in two-dimensional alloy solidification, Int. 536 J. Heat Mass Transfer 35 (7) (1992) 1763-1770. 537

[4] K.C. Chiang, H.L. Tsai, Interaction between shrinkage 538 induced fluid flow and natural convection during alloy 539 solidification, Int. J. Heat Mass Transfer 35 (7) (1992) 540 1771-1778.

[5] Q.Z. Diao, H.L. Tsai, Modeling of solute redistribution in 542 the mushy zone during solidification of Aluminum-Copper 543 alloys, Metall. Trans. A 24 (A) (1993) 963-973. 544

[6] J.H. Chen, H.L. Tsai, Inverse segregation for a unidirec- 545 tional solidification of Aluminum-Copper alloys, Int. J. 546 Heat Mass Transfer 36 (12) (1993) 3069-3075. 547

[7] D. Xu, Q. Li, Numerical method for solution of strongly 548 coupled binary alloy solidification problems, Numer. Heat 549 Trans. A 20 (1991) 181-201.

[8] D. Xu, Q. Li, Gravity and solidification shrinkage induced liquid flow in a horizontally solidified alloy ingot, Numer. Heat Trans. A 20 (1991) 203-221.

[9] A.V. Reddy, C. Beckermann, Modeling of macrosegregation due to thermal-solutal convection and contractiondriven flow in direct chill continuous casting of an $\mathrm{Al}-\mathrm{Cu}$ round ingot, Metall. Trans. B 28 (B) (1997) 479-489.

[10] E. Mcbridge, J.C. Heinrich, D.R. Poirier, Numerical simulation of incompressible flow driven by density variations during phase change, Int. J. Numer. Meth. Fluids 31 (1999) 787-800.

[11] S.D. Felicilli, J.C. Heinrich, D.R. Poirier, Finite element analysis of directional solidification of multicomponent alloys, Int. J. Numer. Meth. Fluids 27 (1998) 207-227.

[12] D.A Weirauch, M.G. Chu, A. Giron, L.J. Martorik, D.P. Ziegler, M. Morishita, K. Nakayama, K. Tokuda, K. Yoskhikawa, Final Report: Kobe-Alcoa collaboration on cast aluminum surface structure, Report No. 99-107, 1999, Alcoa Technical Center, PA 15069-0001.

[13] L. Hector, J. Howarth, O. Richmond, W. Kim, Mold surface wavelength effects on gap nucleation in solidfication, J. Appl. Mech. 67 (2000) 155-159.

[14] T.E. Tezduyar, S. Mittal, S.E. Ray, R. Shih, Incompressible flow computations with stabilized bilinear and linear equal-order-interpolation velocity pressure elements, Comp. Meth. Appl. Mech. Eng. 95 (1992) 221-242.

[15] T.E. Tezduyar, Stabilized finite element formulations for incompressible flow computations, Adv. Appl. Mech. 28 (1992) 1-43.

[16] T.E. Tezduyar, Y. Osawa, Finite element stabilization parameters computed from element matrices and vectors, Comp. Meth. Appl. Mech. Eng. 190 (2000) 411-430.

[17] R. Sampath, N. Zabaras, Numerical study of convection in the directional solidification of a binary alloy driven by the combined action of buoyancy, surface tension and electromagnetic forces, J. Comp. Phys. 168 (2001) 384 411.

[18] D. Samanta, N. Zabaras, Modeling convection in solidification processes using stabilized finite element techniques, Int. J. Numer. Meth. Eng., submitted for publication.

[19] N. Zabaras, D. Samanta, A stabilized volume-averaged finite element method for flow in porous media and binary 
alloy solidification processes, Int. J. Numer. Meth. Eng. 60 (6) (2004) 1103-1138.

[20] W. Shyy, H.S. Udaykumar, M.M. Rao, R.W. Smith, Computational Fluid Dynamics with Moving Boundaries, first ed., Tailor and Francis, Washington, DC, 1996.

[21] F.P. Incropera, W.D. Bennon, A continuum model for momentum, heat and species transport in binary solidliquid phase change systems-I. Model formulation, Int. J. Heat Mass Transfer 30 (1987) 2167-2170.

[22] W.D. Bennon, F.P. Incropera, A continuum model for momentum, heat and species transport in binary solidliquid phase change systems-II. Application to solidifica- tion in a rectangular cavity, Int. J. Heat Mass Transfer 30604 (1987) 2171-2187.

[23] J. Ni, C. Beckermann, A volume-averaged two-phase 606 model for transport phenomena during solidification, 607 Metall. Trans. B 22 (1990) 349-361.

[24] S.D. Felicilli, J.C. Heinrich, D.R. Poirier, Numerical 609 model for dendritic solidification of binary alloys, Numer. 610 Heat Trans. B 23 (1993) 461-481.

[25] M.J.M. Krane, F.P. Incropera, Analysis of the effect of 612 shrinkage on macrosegregation in alloy solidification, 613 Transport Phenomena in Solidification, ASME HTD- 614 Vol. 284/AMD Vol. 182, ASME, New York, 1994, pp. 615 $13-27$. 